\title{
A clinical study of neurological disorders in peripartum period
}

\author{
Borah Papori', Khakhlari AR², Das Marami, Goswami Munindra ${ }^{4}$, Kayal Ashok \\ Received on January 10, 2017; editorial approval (revised) on January 15, 2018
}

\begin{abstract}
Background: Identification and treatment of neurological disorders in women during the peripartum period presents a special challenge to the neurologist and other health providers since this state can precipitate a myriad of new neurologic and psychiatric symptoms. The lack of knowledge is due to the fact that research on pregnant woman is technically difficult, challenging \& highly regulated due to ethical concerns. Objectives: This study was planned to study the clinical profile of various neurological disorders seen during the peripartum period. Materials and methods: This prospective observational study was carried out among 34,302 pregnant patients of age $\geq 16 \mathrm{yrs}$ presenting to our department (or OPD) of Neurology or Department of Obstetrics and Gynaecology (or OPD)between October 2011 to November 2013. Results: A total of 200 patients presented during pregnancy or puerperium with neurological disorders during the study period. $50.5 \%$ of the cases were diagnosed with eclampsia, followed by AIDP in $24.5 \%$ cases. Maximum number of patients presented with convulsion (67\%), followed by altered sensorium (59.0\%). Among 24 patients with stroke, the number of patients with non-hemorrhagic and hemorrhagic stroke was $16(66.66 \%)$ and $8(33.34 \%)$ respectively. Conclusion: We found multi axial involvement and broad range of neurological disorders in the peripartum period with ecclampsia and stroke topping the list. The incidence of AIDP was significantly high, the establishment of cause of which needs further studies.
\end{abstract}

Keywords: Acute Inflammatory Demyelinating Polyradiculoneuropathy; convulsions; eclampsia; migraine; stroke.

\section{INTRODUCTION}

The range of neurological conditions affecting woman of reproductive age is extremely broad. ${ }^{1-2}$ The state of pregnancy and puerperium heralds enormous and rapid women experience rapid physiological changes precipitating new neurologic or psychiatric symptoms. The humongous adaptations and modifications in neuronatomy reproductive endocrinology, systemic \& cerebral circulation and coagulation profile and metabolism can predispose to the onset or deterioration of various neurological disorders. The lack of knowledge is due to the fact that research on pregnant woman is technically difficult, challenging \& highly regulated due to ethical concerns. Various neurological conditions commonly seen in pregnant women and puerperium are Epilepsy, Eclampsia, Cerebrovascular disorders, peripheral neuropathy (Acute Inflammatory Demyelinating Polyradiculoneuropathy, AIDP), Intra Cerebral Hemorrhage (ICH) \& Cerebral Venous Thrombosis (CVT) among others. Certain disorders are found to be more common in peripartum period which includes last $10 \%$ of gestational period, i.e., last 1 month of gestation up to few weeks after delivery with references to the mother. There are very few studies in our country to know the extent of this problem. With this background in mind we planned to undertake this study.

This paper has aimed to study the clinical profile of various neurological disorders seen during peripartum period and to investigate the etiological factors of it.

\section{MATERIALSAND METHODS}

This is a prospective observational study conducted in the department of Neurology, GMCH, Guwahati during the period from October 2011 to November 2013. Cases were selected of age $\geq 16$ yrs presenting to the Department of Neurology or Department of Obstetrics and Gynaecology or attending the Neurology, Obstetrics OPDs using stringent inclusion and exclusion criteria with the approval of ethical committee.

Statistical analysis were performed using the Microsoft

Address for Corresspondence:
${ }^{1}$ Assistant Professor of Neurology
${ }^{2}$ Assistant Professor (Corresponding author)
Email ID: khakhlariarjunroy@gmail.com
Department of Anesthesiology
3Professor, ${ }^{4}$ Professor, ${ }^{5}$ Rtd. Professor
Dept. of Neurology
Gauhati Medical College \& Hospital, Assam

Address for Corresspondence:

Assistant Professo

${ }^{2}$ Assistant Professor (Corresponding author)

Email ID: khakhlariarjunroy@gmail.com

Department of Anesthesiology

${ }^{3}$ Professor, ${ }^{4}$ Professor, ${ }^{5}$ Rtd. Professor

Gauhati Medical College \& Hospital, Assam 
Excel program, 2007 edition and the GraphPad INSTAT4 program. In the course of the evaluation of the data gathered, descriptive statistical methods (average, standard deviation) were used. The results of these tests were considered at the significance level of $p<0.05$ and the confidence interval $95 \%$.

\section{RESULTS}

A total of 200 patients presented during pregnancy or puerperium with neurological disorders during the study period between October 2011 to November 2013. The total number of deliveries in this period in this hospital was 34,302, giving an incidence of 583.06 per 1, 00,000 of deliveries. The mean age was $24.06 \pm 4.913$ (95\% CI:23.379- 24.741), of which $160(80 \%)$ were primigravida and rest $40(20 \%)$ were multigravida.

Table 1 Showing the demographic data of the study population

\begin{tabular}{|l|l|}
\hline Parameter & Value \\
\hline $\begin{array}{l}\text { Age (yr) } \\
\text { Mean } \pm \text { SD }\end{array}$ & $24.06 \pm 4.913$ \\
\hline $95 \%$ CI & $23.379-24.741$ \\
\hline Range & $16-40$ \\
\hline $\begin{array}{l}\text { ParityPrimigravida } \\
\text { (total no with \% in bracket) }\end{array}$ & $160(80.0)$ \\
\hline $\begin{array}{l}\text { Multigravida } \\
\text { (total no with \% in bracket) }\end{array}$ & $40(20.0)$ \\
\hline
\end{tabular}

Spectrum of Neurological Disorders in Peripartum Women:

Two hundred patients presented with new onset peripartum neurological disorders. Eclampsia was diagnosed in 101 out of 200 patients $(50.5 \%)$. The incidence of eclampsia was 294.44 per 1,00,000 deliveries.

Maximum number of patients presented with convulsion (67\%), followed by altered sensorium (59.0\%). 30\% patients had some degree of muscular weakness and $23 \%$ patients presented with symptoms suggestive of cranial nerve involvement e.g. inability to swallow, pooling of saliva, facial deviation etc. The most common presenting symptom was seizure. 134 out of 200 patients $(67 \%)$ presented with new onset seizure.

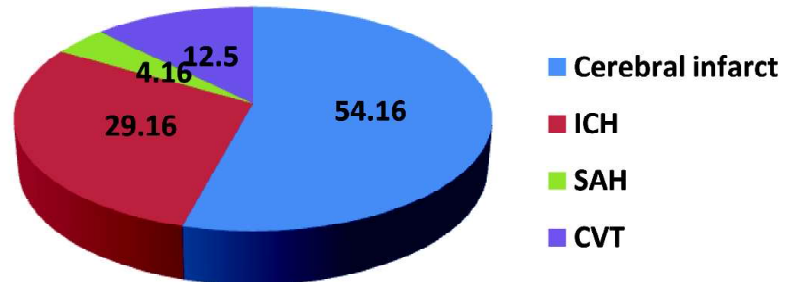

Figure 1 Types of stroke seen in peripartum period

(ICH : Intracerebral Hemorrhage. SAH : Subarachnoid Hemorrhage. CVT : Cerebral venous thrombosis)

Table 2 Spectrum of neurological disorders during peripartum period

\begin{tabular}{|c|c|c|c|}
\hline $\begin{array}{l}\text { Neurological } \\
\text { disorder }\end{array}$ & $\begin{array}{l}\text { Number of } \\
\text { cases }\end{array}$ & Percentage & $\begin{array}{l}\text { Incidence per } \\
\mathbf{1 , 0 0 , 0 0 0} \\
\text { deliveries }\end{array}$ \\
\hline Eclampsia & 101 & 50.5 & 294.44 \\
\hline AIDP & 49 & 24.5 & 142.85 \\
\hline Stroke & 24 & 12.00 & 69.96 \\
\hline $\begin{array}{l}\text { Tubercular } \\
\text { Meningitis } \\
\text { (TBM) }\end{array}$ & 4 & 2 & 11.66 \\
\hline $\begin{array}{l}\text { Spinal Cord } \\
\text { Pathology }\end{array}$ & 3 & 1.5 & 8.74 \\
\hline $\begin{array}{l}\text { Metabolic } \\
\text { Encephalop- } \\
\text { athy due to } \\
\text { Dyselectroly- } \\
\text { temia }\end{array}$ & 3 & 1.5 & 8.74 \\
\hline Migraine & 2 & 1 & 5.83 \\
\hline $\begin{array}{l}\text { Prolapsed } \\
\text { Intervertebral } \\
\text { Disc Lesion } \\
\text { (PIVD) }\end{array}$ & 2 & 1 & 5.83 \\
\hline $\begin{array}{l}\text { Encephalo- } \\
\text { myelitis }\end{array}$ & 2 & 1 & 5.83 \\
\hline Bell‘s palsy & 2 & 1 & 5.83 \\
\hline $\begin{array}{l}\text { Septic Encep- } \\
\text { halopathy }\end{array}$ & 2 & 1 & 5.83 \\
\hline $\begin{array}{l}\text { Cerebellar } \\
\text { ataxia }\end{array}$ & 1 & 0.5 & 2.91 \\
\hline $\begin{array}{l}\text { Space } \\
\text { Occupying } \\
\text { Lesion(SOL) }\end{array}$ & 1 & 0.5 & 2.91 \\
\hline $\begin{array}{l}\text { Sensory } \\
\text { neuropathy }\end{array}$ & 1 & 0.5 & 2.91 \\
\hline $\begin{array}{l}\text { Altered } \\
\text { sensorium } \\
\text { of undete- } \\
\text { rmined origin }\end{array}$ & 3 & 1.5 & 8.74 \\
\hline
\end{tabular}




\section{Presenting symptoms:}

Table 3 Presenting symptoms of neurological disorders in peripartum period

\begin{tabular}{|l|l|l|}
\hline Presenting symptom & No of cases & Percentage \\
\hline Altered consciousness & 118 & 59.0 \\
\hline Convulsion & 134 & 67.0 \\
\hline Muscular weakness & 60 & 30 \\
\hline $\begin{array}{l}\text { Symptoms suggestive of } \\
\text { cranial nerve involvement }\end{array}$ & 46 & 23 \\
\hline Sensory abnormality & 13 & 6.5 \\
\hline Fever & 7 & 3.5 \\
\hline Nausea/vomiting & 4 & 2 \\
\hline Headache & 11 & 5.5 \\
\hline Abnormal movement & 1 & 0.5 \\
\hline
\end{tabular}

Types of strokes seen in peripartum period were cerebral infarct $(54.16 \%), \operatorname{ICH}(29.16 \%), \operatorname{CVT}(12.5 \%)$ and $\mathrm{SAH}(4.16 \%)$.

Table 4 Etiology of non-hemorrhagic stroke in peripartum period

\begin{tabular}{|l|c|}
\hline \multicolumn{2}{|c|}{ Non hemorrhagic stroke (16 nos) } \\
\hline Cause & No of cases \\
\hline CVT & 3 \\
\hline Leukaemia & 1 \\
\hline Postpartum angiopathy & 1 \\
\hline Undetermined & 11 \\
\hline
\end{tabular}

Table 5 Etiology of hemorrhagic stroke in peripartum period

\begin{tabular}{|l|l|l|l|}
\hline \multicolumn{4}{|c|}{ Hemorrhagic stroke (8 nos) } \\
\hline Intra-cerebral hemorrhage & \multicolumn{2}{|c|}{ Subarachnoid hemorrhage } \\
\hline Cause & No of cases & Cause & No of cases \\
\hline AVM & 1 & $\begin{array}{l}\text { Undetermined } \\
\text { cause of SAH }\end{array}$ & 1 \\
\hline Undetermined & 6 &
\end{tabular}

Among 24 patients with stroke, the number of patients with non-hemorrhagic and hemorrhagic stroke was $16(66.66 \%)$ and $8(33.34 \%)$ respectively. Postpartum angiopathy was seen in only one patient who had no previous history of hypertension.

\section{DISCUSSION}

We observed an incidence of new onset neurological disorders of 583.06 per 1,00,000 deliveries, which is similar

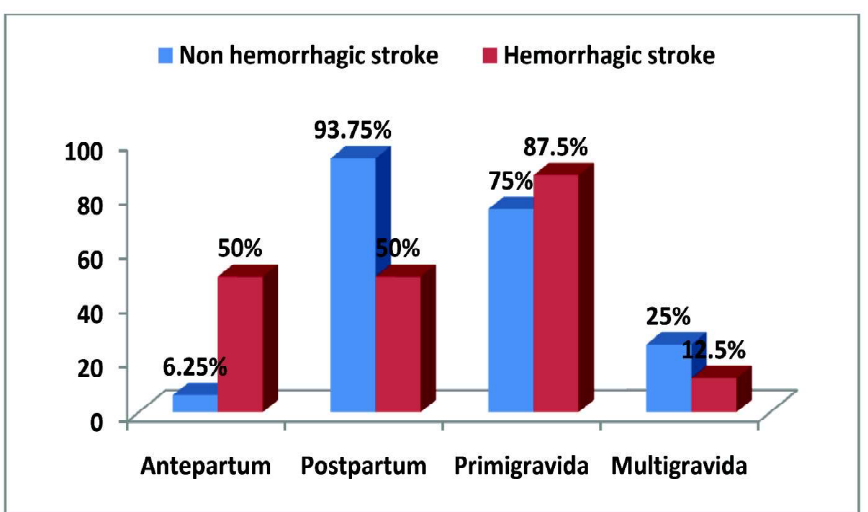

Figure 2 Comparison of timing and parity of the patients with hemorrhagic and non-hemorrhagic stroke

to a study by Gupta $\mathrm{S}$ et al, ${ }^{3}$ who reported an incidence of 584 per 1,00,000 deliveries. However, Gupta $\mathrm{S}$ et $\mathrm{al}^{3}$ in their study excluded patients with eclampsia but included patients with pre-existing neurological disorders. By retrospectively examining the database of 10 years in a hospital at Hong Kong, To WK et al, ${ }^{4}$ reported the incidence of neurological disorder as 326 per 1,00,000 pregnancies. Thus the reported incidence varies significantly across different studies. Since the inclusion and exclusion criteria varies among these studies, the study population across these studies are not comparable. The distribution of incidence of eclampsia varies across the globe. Europe, USA and eastern parts of Asia enjoy a low incidence whereas it is high in India. The mean age with SD of patients presenting with new onset neurological disorder in our study was $24.06 \pm 4.913,80.0 \%$ of them were primigravida and $20 \%$ were multigravida. $60.5 \%$ of these patients presented in their postpartum period. We could not gather any information regarding these parameters in various studies even after a careful search of literature.

Spectrum of neurological disorders in peripartum women: In our study the highest number of patients were diagnosed with eclampsia (50.5\%) followed by AIDP (24.5\%), Stroke $(12.00 \%)$ and other less prevalent disorders.

Eclampsia is defined as seizures in a woman with preeclampsia that cannot be attributed to any other cause. ${ }^{5}$ In our study, the incidence of eclampsia was 294.44 per 1,00,000 deliveries. The mean age with SD was $23.356 \pm 4.78$ years, $84.16 \%$ were primigravida and $57.43 \%$ presented during postpartum period. This is in sync with a study by Al-hayali et $\mathrm{al}^{6}$, who reported a mean age with SD of their patient population as $23.47 \pm 5.32$ years with $85 \%$ primigravida and $60 \%$ presented during antepartum period. Although many studies carried out in India have excluded eclampsia from their patient population. ${ }^{3,5,7,8}$, the one reported by Singh $\mathrm{S}$ et $\mathrm{al}^{9}$ estimates the incidence to be $3.2 \%, 82.27 \%$ were primigravida and $18.4 \%$ presented during postpartum period. To $\mathrm{WK}$ et $\mathrm{al}^{4}$ reported an incidence of 39 per 1,00,000 pregnancies but no data regarding the parity status or timing of presentation was shown. The mean age and parity status of eclamptic 
patients in our study correlates well with the studies by Singh $\mathrm{S}$ et $\mathrm{al}^{9}$ and Al-Hayali RM et al. ${ }^{6}$ But in these two studies maximum patients presented during antepartum period, whereas we observed maximum incidence during postpartum period. Neuroimaging revealed features suggestive of hypertensive encephalopathy/Posterior Reversible Encephalopathic Syndrome (PRES) and cerebral oedema in all patients with eclampsia.

\section{Stroke}

In our study the incidence of stroke was found to be 69.96 per 1,00,000 deliveries.Our observation correlates with that of Jaigobin C et al (69\%). ${ }^{10}$ Whereas Sharshar $\mathrm{T}$ et $\mathrm{al}^{11}$ reported a lower incidence of $8.9 \%$. Both the study by us and Jaigobin et $\mathrm{al}^{10}$ are studies carried out in single tertiary care hospital, whereas the study by Sharshar $\mathrm{T}$ et $\mathrm{al}^{11}$ was carried out in 63 public maternities. As some studies examining the incidence of stroke in peripartum period is population-based whereas some others are single-hospital based studies, it is difficult to arrive at a consensus regarding the exact incidence. The percentage of patients with stroke in our study was $12 \%$, and it correlates with that of Gupta $\mathrm{S}$ et al $(11.9 \%){ }^{3}$ But the incidence that is reported in studies by Janaki et al $(49.5 \%),{ }^{7}$ Agarwal K $(82.7 \%)^{8}$ and Srinivasan $\mathrm{K}$ et al $(60.3 \%)^{5}$ is higher than in this study. It may be because of the less cases of CVT $(1.5 \%$ in our study and $6.6 \%$ in study by Gupta $\mathrm{S}$ et $\mathrm{al}^{3}$ ) as compared to these studies where CVT accounted for $35-65 \%$ of the cases . Regarding the timing of pregnancy associated stroke, different studies provide conflicting results. It has been recently reported that the risk is greatest during the postpartum period..$^{10}$ In our study most patients presented in the postpartum period $(79.17 \%)$. It has been suggested that large reduction of blood volume following delivery, hormonal changes, hypercoagulability of pregnancy state, dehydration, anaemia following child delivery increases the incidence of stroke in the postpartum period.

In prior studies, only in a small proportion of patients an etiologic diagnosis of stroke could be reached. ${ }^{10}$ The proportion of patients during peripartum period presenting with non-hemorrhagic stroke is frequently reported to be more than those presenting with hemorrhagic stroke. ${ }^{3,10}$ In our study $66.66 \%$ presented with non-hemorrhagic stroke. Whereas, Sharshar $\mathrm{T}$ et $\mathrm{al}^{11}$ reported that the percentage of patients with hemorrhagic and non-hemorrhagic stroke is equal, it is assumed that the majority of strokes associated with pregnancy are secondary to venous thrombosis. ${ }^{12}$ Two recent studies by Kalita $\mathrm{J}$ et $\mathrm{al}^{13}$ and Narayan $\mathrm{D}$ et al ${ }^{12}$ from India identified peripartum period as a risk factor for CVT. In our study, all the 3 patients with CVT were confirmed with appropriate neuroimaging technique and they presented during postpartum period. In the present study due to socio cultural reason, less number of patients had CVT. In other parts of India a pregnant women is subjected to restrictions in relation to food and movement. This however is not practised in Assam.

\section{AIDP}

49 out of 200 patients were diagnosed with AIDP, the incidence being 142.85 per 1,00,000 deliveries. It is generally regarded that the incidence of Guillain -Barre Syndrome (GBS) during pregnancy is similar to that of general population. ${ }^{14}$ Chan LY et al ${ }^{15}$ mentioning the work of Alter M et $\mathrm{al},{ }^{16}$ reported that incidence of GBS range from 0.6 to $4.0 /$ $1,00,000$ population. Compared to these data, the incidence in our study is alarmingly high. Though the exact reason behind it is not known to us and should be investigated, postpartum flairs are common due to delayed hypersensitivity, immunization, acute infection and surgical procedure. ${ }^{17}$ In our study, $71.42 \%$ presented during postpartum period. Chan LY et a ${ }^{15}$ also observed increased incidence during postpartum period with a rate ratio of $2.93(95 \%$ CI $1.20-7.11)$ during the first 30 days after delivery. Primigravida accounted for $75.5 \%$ patients with AIDP.

In our study, 5 patients $(10.20 \%)$ needed mechanical ventilatory support while $6.12 \%$ of patients died. This is in contrast to an earlier study by Nelson LH et a $1^{18}$ that as many as $34.5 \%$ of women suffering from GBS during pregnancy required ventilatory support and the maternal mortality exceeded $10 \%$. Out of 24 patients who followed up during the study period, 18 patients had complete recovery and 6 patients had residual weakness at 6 months and remaining are not in follow up.

In our study, $2 \%$ patients presented with TBM, in contrast to that reported by Gupta $\mathrm{S}$ et al, ${ }^{3}(15.8 \%)$, whereas other study done by Janaki $\mathrm{S}$ et al. ${ }^{7}$ Agarwal K et al, ${ }^{8}$ Srinivasan K et $\mathrm{al},{ }^{5}$ reported low percentages of CNS infection $(4.1 \%$, $5.7 \%, 4.4 \%$ respectively). All these studies included broader term "CNS infection", without mention of specific etiology. So incidence of TBM is not comparable to our study. Neurological diseases may be incidental to pregnancy (e.g., meningitis), usually presenting with classical manifestations. It commonly occurs between the $5^{\text {th }}$ and $7^{\text {th }}$ months or in the postpartum period. Most patients improve with treatment (Gupta S et al). ${ }^{3}$ Our patients with TBM, mostly presented during post partum period and responded to treatment.

In our study, spinal cord pathology was found in 3(1.5\%) patients, similar to Gupta $\mathrm{S}$ et $\mathrm{al}^{3}(1.5 \%)$ and in contrast to Srinivasan $\mathrm{S}$ et $\mathrm{al}^{5}(7.4 \%)$. Our study is the first in India to report occurrence of cerebellar ataxia $(0.5 \%)$. One patient had hyperemesis gravidarum, leading to nutritional deficiency and she responded well to injectable preparation of multivitamins.

$1(0.5 \%)$ patient was diagnosed with pretectal space occupying lesion with hydrocephalus. Prior to this pregnancy she was asymptomatic. Agarwal et $\mathrm{al}^{8}$ and Gupta $\mathrm{S}$ et $\mathrm{al}^{3}$ observed that $1.1 \%$ and $1.3 \%$ patients presented with SOL respectively. To WK et al, ${ }^{4}$ Janaki et $\mathrm{al}^{7}$ and Srinivasan et $\mathrm{al}^{5}$ reported higher percentage $(7.5 \%, 7.2 \%$ and $23.5 \%$ respectively). Usually there is an increase in the size of the tumour during pregnancy due to hormonal changes and amelioration of symptoms in the postpartum period. 
We got 2(1\%) cases of Bell's palsy, one in postpartum period and one in the third trimester. Rosenbaum RB et al, ${ }^{19}$ reported that the incidence of Bell's palsy is higher during pregnancy and the puerperium (38-45 women per 1,00,000 pregnancies v 17 per 1,00,000 women-years in non-pregnant women of childbearing age). In our study, 2(1\%) patients presented with migraine without any antecedent history prior to this pregnancy. Goadsby $\mathrm{PJ}$ et $\mathrm{al}^{20}$ showed that migraine is 3 times more common in women $(3: 1$ ratio) and female headache prevalence is highest during childbearing years. However, studies by Goadsby PJ et al, ${ }^{20}$ Sances G et $\mathrm{al}^{21}$ have shown that the incidence of migraine headache is often reduced during the second 2 trimesters of pregnancy but in our study our patients presented in term pregnancy only.

\section{CONCLUSION}

Neurological disorders are an important cause of mortality and morbidity in reproductive age group. We found multi axial involvement and broad range of neurological disorders in the peripartum period. The most common new onset neurological disorder was Eclampsia followed by AIDP and Stroke. Eclampsia was the most common cause of new onset seizure in the peripartum period followed by stroke. In our study, the incidence of AIDP was very high as compared to other studies. The exact reasons of which needs further investigations.

Ethical clearance: Taken.

Conflict of interest: No conflict of interest associated with this work.

\section{Source of funding: None}

Contribution of Authors: We declared that this work was done by the authors named in this article and all liabilities pertaining to claims relating to the content of this article will be borne by the authors.

\section{REFERENCES}

1. Gold Smith PJ. Neurological disorders of pregnancy. New York: Future Publishing; 1986.

2. Donaldson Jo. Neurology of pregnancy. 2nd ed. London: Saunders; 1989.

3. Gupta S, Rohatgi A, Sharma SK, Gurtoo A . A study of neurological disorders during pregnancy and puerperium. Annals of Indian Academy Of Neurology 2006;9(3):152-7.

4. To WK, Cheung RT. Neurological disorders in pregnancy. Hong Kong Med J 1997;3:400-8.

5. Srinivasan K, Ramamurthi B. Neurological disorders in pregnancy and puerperium. J Assoc Phys India 1971;19:705-13.

6. Rami M. Al hayali RM,Dhaher J,Al Haboo,Mohammed $\mathrm{K}$ Hammo.Peripartum neurological emergencies in a critical care unit. Neurosciences 2008;13(2):155-60.
7. Janaki S, Thomas L. Neurological complications in pregnancy and puerperium. Neurol India 1963;11:12837.

8. Agarwal K. Neurological disorders in pregnancy and puerperium. J Assoc Phys India 1968;19:705-13.

9. S Singh, A Behera. Eclampsia In Eastern India: Incidence, Demographic Profile And Response To Three Different Anticonvulsant Regimes Of Magnesium Sulphate. The Internet Journal of Gynecology and Obstetrics 2010;15:2.

10. Jaigobin C. Silver FL. Stroke and pregnancy. Stroke 2000;31:2948-51.

11. Sharshar T. Lamy C, Mas JL. Incidence and causes of strokes associated with pregnancy and puerperium: a study in public hospitals of Ile de France. Stroke 1995;26:930-6.

12. Narayan D, Kaul S, Ravishankar K, Suryaprabha T, Bandaru VCSS, Mridula, KR, Jabeen SA, Alladi S, Meena $\mathrm{AK}$ and Borgohain R. Risk factors, clinical profile, and long term outcome of 428 patients of cerebral sinus venous thrombosis: Insights from Nizam's Institute Venous Stroke Registry, Hyderabad (India). Neurology India 2012;60(2):154-59.

13. Kalita J, Bansal V, Misra UK. Cerebral venoussinus thrombosis in a tertiary care setting in India. QJM 2006;99(7):491-2.

14. Goyal V, Misra BK, Singh S, Prasad K, Behari M. Acute inflammatory demyelinating polyneuropathy in patients with pregnancy. Neurol India 2004;52:283-4.

15. Chan LY, Tsui MH, Leung TN: Guillain-Barré syndrome in pregnancy. Acta Obstet Gynecol Scand 2004;83:319.

16. Alter M. The epidemiology of GBS. Ann Neurol 1990;8792.

17. Campos da Silva F, de Moraes Paula G, Dos Santos Esteves Automari CV, Mendes de Almeida DS, Ubirajara Cavalcanti Guimarães R. Guillain-Barre syndrome in Pregnancy: Early diagnosis and treatment is essential for a favourable outcome. Gynecol Obstet Invest 2009;67:236-7.

18. Nelson LH, Mclean WT. Management of laundryGuillain barre syndrome in pregnancy. Obstet Gynecol 1985;65:255-95.

19. Rosenbaum RB, Donaldson JO. Peripheral nerve and neuromuscular disorders. Neurol Clin 1994;12:461-77.

20. Goadsby PJ, Lipton RB, Ferrari MD. Migraine- current understanding and treatment. N Engl J Med 2002 Jan 24;346(4):257-70.

21. Sances G, Granella F, Nappi RE. Course of migraine during pregnancy and postpartum: a prospective study. Cephalalgia 2003;23(3):197-205. 